\title{
Finite Element Solution of MHD Transient Flow past an Impulsively Started Infinite Horizontal Porous Plate in a Rotating Fluid with Hall Current
}

\author{
J. Anand Rao ${ }^{1}$, R. Srinivasa Raju ${ }^{2 \dagger}$ and S. Sivaiah ${ }^{3}$ \\ ${ }^{I}$ Department of Mathematics, University College of Science, Osmania University, Hyderabad, 500007, Andhra \\ Pradesh, India. \\ ${ }^{2}$ Department of Basic Science and Humanities, Padmasri Dr. B. V. Raju Institute of Technology, Narsapur, Medak \\ (Dt), 502313, Andhra Pradesh, India. \\ ${ }^{3}$ Department of Mathematics, Gitam University, Hyderabad Campus, Hyderabad, 502329, Andhra Pradesh, India.
}

†Corresponding Author email: srivass999@gmail.com

(Received October 1, 2010; accepted February 20, 2011)

\begin{abstract}
The problem of a transient three dimensional MHD flow of an electrically conducting viscous incompressible rotating fluid past an impulsively started infinite horizontal porous plate taking into account the Hall current is presented. It is assumed that the fluid rotates with a constant angular velocity about the normal to the plate and a uniform magnetic field applied along the normal to the plate and directed into the fluid region. The magnetic Reynolds number is assumed to be so small that the induced magnetic field can be neglected. The non-dimensional equations governing the flow are solved by Galerkin finite element method. The expressions for the primary and secondary velocity fields are obtained in non-dimensional form. The effects of the physical parameters like M (Hartmann number), $\Omega$ (Rotation parameter) and $\mathrm{m}$ (Hall parameter) on these fields are discussed through graphs and results are physically interpreted.
\end{abstract}

Keywords: MHD, Hall current, Rotation, Transient, Horizontal porous plate

\section{INTRODUCTION}

MHD is the science of motion of electrically conducting fluid in presence of magnetic field. There are numerous examples of application of MHD principle. Engineers apply MHD principle in fusion reactors, dispersion of metals, metallurgy, design of MHD pumps, MHD generators and MHD flow meters etc. The dynamo and motor is a classical example of MHD principle. Geophysics encounters MHD characteristics in the interaction of conducting fluid and magnetic field. MHD convection problems are also very significant in fields of Stellar and Planetary magnetospheres, aeronautics and chemical and electrical Engineering. The MHD principle also finds its application in Medicine and Biology. Application in biomedical engineering includes cardiac MRI, ECG etc. The principle of MHD is also used in stabilizing a flow against the transition from laminar to turbulent flow.

MHD, in its present form is due to the pioneer contributions of several notable authors. It was emphasized by Cowling (1957) that when the strength of the magnetic field is sufficiently large, Ohm's law needs to be modified to include Hall current. The Hall effect is due merely to the sideways magnetic force on the drifting free charges. The electric field has to have a component transverse to the direction of the current density to balance this force. In many works on plasma physics, the Hall effect is ignored. But if the strength of magnetic field is high and the number density of electrons is small, the Hall effect cannot be disregarded as it has a significant effect on the flow pattern of an ionized gas. Hall effect results in a development of an additional potential difference between opposite surfaces of a conductor for which a current is induced perpendicular to both the electric and magnetic field. This current is termed as Hall current. Model studies on the effect of Hall current on MHD convection flows have been carried out by many authors due to application of such studies in the problems of MHD generators and Hall accelerators.

Some of them are Datta and Jana (1976) studied oscillatory magneto hydrodynamic flow past a flat plate with Hall Effect. Das et al. (1996) studied the radiation effects on flow past an impulsively started vertical plate an exact solutions. Muthucumaraswamy and Ganesan (1998) investigated the unsteady flow past an impulsively started vertical plate with heat and mass transfer. Singh (2000) studied an oscillatory hydromagnetic couette flow in a rotating system. 
Aboeldahab and Elbarbary (2001) investigated hall current effect magnetohydrodynamics free convection flow past a semi infinite vertical plate with mass transfer. Acharya et al. (2001) discussed Hall Effect with simultaneous thermal and mass diffusion on unsteady hydromagnetic flow near an accelerated vertical plate. Kinyanjui et al. (2001) presented magnetohydrodynamic free convection heat and mass transfer of a heat generating fluid past an impulsively started infinite vertical porous plate with hall current and radiation absorption. Ganesan and Palani (2002) studied the effects of mass transfer on the MHD flow past an impulsively started isothermal inclined plate. Takhar et al. (2002) studied MHD flow over a moving plate in a rotating fluid with magnetic field, hall currents and free stream velocity. Abdul Maleque and Abdul Sattar (2005) studied the effects of variable properties and Hall current on steady MHD laminar convective fluid flow due to a porous rotating disk. Prasad et al. (2006) reported transient radiative hydromagnetic free convection flow past an impulsively started vertical plate with uniform heat and mass flux. Prasad et al. (2007) studied the radiation and mass transfer effects on two-dimensional flow past an impulsively started infinite vertical plate. Sharma et al. (2007) studied the Hall Effect on MHD mixed convective flow of a viscous incompressible fluid past a vertical porous plate immersed in porous medium with heat source/sink. Chaudhary and Kumar Jha (2008) discussed the heat and mass transfer in elastico viscous fluid past an impulsively started infinite vertical plate with hall effect. Heat and Mass transfer. Palani and Abbas (2009) studied the free convection MHD flow with thermal radiation from an impulsively started vertical plate.

The rotating flow of an electrically conducting fluid in presence of a magnetic field is encountered in Geophysical fluid dynamics. It is also important in the solar physics dealing with the sunspot development, the solar cycle and the structure of rotating magnetic stars. It is well known that a number of astronomical bodies possess fluid interiors and magnetic fields. Changes that takes place in the rate of rotation, suggest the possible importance of hydromagnetic spin-up. Many authors have studied this problem of spin-up in MHD under different conductions of whom the names of Singh (2000) and Takhar et al. (2002) are worth mentioning. Prasad et al. (2011) discussed finite difference analysis of radiative free convection flow past an impulsively started vertical plate with variable heat and mass flux. Vasu et al. (2011) studied the radiation and mass transfer effects on transient free convection flow of a dissipative fluid past semi-infinite vertical plate with uniform heat and mass flux.

Due to importance of studying MHD flow problems in rotating fluid, we have proposed in the present paper to investigate the problem of the unsteady MHD flow of an electrically conducting viscous fluid past a suddenly started infinite horizontal porous plate taking into account the effect of Hall current. Here our main objective is to study the effects of the magnetic field, rotation of the fluid and Hall current on the velocity fields and skin frictions at the plate.

\section{MATHEMATiCAL Formulation}

The equations governing the motion of an incompressible viscous electrically conducting rotating fluid in presence of a magnetic field are

Equation of continuity:

$\vec{\nabla} \cdot \vec{q}=0$

Momentum equation:

$\rho\left[\frac{\partial \vec{q}}{\partial t^{\prime}}+\vec{\Omega} \times \vec{q}+(\vec{q} \cdot \vec{\nabla}) \vec{q}\right]=-\vec{\nabla} p+\vec{J} \times \vec{B}$

$+\mu \nabla^{2} \vec{q}$

Kirchhoff's law:

$\vec{\nabla} \cdot \vec{J}=0$

General Ohm's law:

$\vec{J}+\frac{\omega_{e} \tau_{e}}{B_{o}}(\vec{J} \times \vec{B})=\sigma\left[\vec{E}+(\vec{q} \times \vec{B})+\frac{1}{e \eta_{e}} \vec{\nabla} p_{e}\right]$

Gauss's law of magnetism:

$\vec{\nabla} \cdot \vec{B}=0$

Where $\vec{q}$ is the velocity vector, $\vec{\Omega}$ the angular velocity of the fluid, $\rho$ the fluid density, $\mathrm{p}$ the pressure, $\vec{\jmath}$ the current density, $\vec{B}$ the magnetic induction vector, $\mu$ the coefficient of viscosity, $\sigma$ the electrical conductivity, $t^{\prime}$ the time, $B_{0}$ the strength of the applied magnetic field, $\omega_{e}$ the electron frequency, $\tau_{e}$ the electron collision time, e the electron charge, $\eta_{e}$ the number density of electron, $P_{e}$ the electron pressure, $\vec{E}$ the electric field and the other symbols have their usual meanings.

We now consider an unsteady flow of an incompressible viscous electrically conducting rotating fluid past a suddenly started infinite horizontal porous plate with constant suction in presence of a uniform transverse magnetic field taking into account the effect of Hall current. Our investigation is restricted to the following assumptions.

i) All the fluid properties are constants and the buoyancy force has no effect on the flow.

ii) The plate is electrically non-conducting.

iii) The fluid is rotating with angular velocity $\vec{\Omega}$ about the normal to the plate.

iv) The magnetic Reynolds number is so small that the induced magnetic field can be neglected.

v) $P_{e}$ is constant

vi) $\vec{E}=0$

vii) The fluid away from the plate is undisturbed due to rotation

Initially the plate was at rest and the fluid was rotating about the normal to the plate. At time $t^{\prime}>0$, the plate is suddenly moved in its own plane with velocity $U_{0}^{\prime}$ and which is thereafter maintained constant. 
We introduce a coordinate system $\left(x^{\prime}, y^{\prime}, z^{\prime}\right)$ with Xaxis horizontally in the direction of the plate velocity, $\mathrm{Y}$-axis horizontally in the direction of the secondary velocity and $\mathrm{Z}$-axis along the normal to the plate which is the axis of rotation. Let $\vec{q}=\hat{\imath} u^{\prime}+\hat{\jmath} v^{\prime}+\hat{k} w^{\prime}$ be the fluid velocity, $\vec{J}=J^{\prime}{ }_{x} \hat{\imath}+J^{\prime}{ }_{y} \hat{\jmath}+J^{\prime}{ }_{z} \hat{k}$ be the current density at the point $P^{\prime}\left(x^{\prime}, y^{\prime}, z^{\prime}\right)$ and $B^{\prime}=B_{0} \hat{k}$ be the applied magnetic field, $\hat{\imath}, \hat{\jmath}, \hat{k}$ being the unit vectors along $\mathrm{X}$-axis, $\mathrm{Y}$-axis and $\mathrm{Z}$-axis respectively.

As the plate is infinite in X-direction and Y-direction, therefore all the quantities except possibly the pressure are independent of $x^{\prime}$ and $y^{\prime}$.

The Eq. (1) gives $\frac{\partial w^{\prime}}{\partial z^{\prime}}=0$

which is trivially satisfied by $\vec{w}=-w_{o}^{\prime}$

$w_{o}^{\prime}$ being the suction velocity.

Therefore the velocity vector $\vec{q}$ is given by

$\vec{q}=\hat{i} u^{\prime}+\hat{j} v^{\prime}-\hat{k} w_{o}^{\prime}$

The Eq. (5) is satisfied by $\vec{B}=B_{o} \hat{k}$

The Eq. (3) reduces to $\frac{\partial J_{z}^{\prime}}{\partial z^{\prime}}=0$ which shows that

$J_{z}^{\prime}=0$

(as the plate is electrically non-conducting)

Hence the current density is given by

$\vec{J}=J_{x}^{\prime} \hat{i}+J_{y}^{\prime} \hat{j}$

Under the assumptions (v) and (vi), the Eq. (4) takes the form:

$$
\vec{J}+\frac{m}{B_{o}}(\vec{J} \times \vec{B})=\sigma(\vec{q} \times \vec{B})
$$

Where $m=\omega_{e} \tau_{e}$ is the Hall parameter. The Eqs. (8), (9), (11) and (12) yields,

$$
\begin{aligned}
& J_{x}^{\prime}=\frac{\sigma B_{o}}{1+m^{2}}\left(m u^{\prime}+v^{\prime}\right) \\
& J_{y}^{\prime}=\frac{\sigma B_{o}}{1+m^{2}}\left(m v^{\prime}-u^{\prime}\right)
\end{aligned}
$$

With foregoing assumptions and under the usual boundary layer and Boussinesq's approximation the Eq. (2) reduces to

$$
\begin{aligned}
& \frac{\partial u^{\prime}}{\partial t^{\prime}}-w_{o}^{\prime} \frac{\partial u^{\prime}}{\partial z^{\prime}}-\Omega^{\prime} v^{\prime}=v \frac{\partial^{2} u^{\prime}}{\partial z^{\prime 2}}+\frac{\sigma B_{o}^{2}\left(m v^{\prime}-u^{\prime}\right)}{\rho\left(1+m^{2}\right)} \\
& \frac{\partial v^{\prime}}{\partial t^{\prime}}-w_{o}^{\prime} \frac{\partial v^{\prime}}{\partial z^{\prime}}+\Omega^{\prime} v^{\prime}=v \frac{\partial^{2} v^{\prime}}{\partial z^{\prime 2}}+\frac{\sigma B_{o}^{2}\left(m u^{\prime}+v^{\prime}\right)}{\rho\left(1+m^{2}\right)}
\end{aligned}
$$

Where $w_{0}^{\prime}$ is the constant suction velocity and $v$ is the kinematic viscosity. The relevant initial and boundary conditions are

$$
\left.\begin{array}{l}
u^{\prime}=0, v^{\prime}=0 \text { for } t^{\prime} \leq 0 \quad \forall \mathrm{z} \\
u^{\prime}=U_{o}^{\prime}, v^{\prime}=0 \text { at } z^{\prime}=0 \\
u^{\prime}=0, v^{\prime}=0 \text { at } z^{\prime} \rightarrow \infty
\end{array}\right\} \forall t^{\prime}>0
$$

We introduce the following non-dimensional variables and parameters.

$$
\begin{aligned}
& z=\frac{w_{o}^{\prime} z^{\prime}}{v}, t=\frac{w_{o}^{\prime 2} t^{\prime}}{v}, u=\frac{u^{\prime}}{U_{o}^{\prime}}, v=\frac{v^{\prime}}{U_{o}^{\prime}}, \\
& M=\frac{\sigma B_{o}^{2} v}{\rho w_{o}^{\prime 2}}(\text { Hartmann number }), \Omega=\frac{\vec{\Omega} v}{v_{o}^{2}}
\end{aligned}
$$

The non-dimensional form of the Eqs. (15) and (16) are

$\frac{\partial u}{\partial t}-\frac{\partial u}{\partial z}-\Omega v=\frac{\partial^{2} u}{\partial z^{2}}+\frac{M}{1+m^{2}}(m v-u)$

$\frac{\partial v}{\partial t}-\frac{\partial v}{\partial z}+\Omega u=\frac{\partial^{2} v}{\partial z^{2}}+\frac{M}{1+m^{2}}(m u+v)$

Subject to the initial and boundary conditions

$u=0, v=0$ for $t \leq 0 \quad \forall \mathrm{z}$

$\left.\begin{array}{l}u=1, v=0 \text { at } z=0 \\ u=0, v=0 \text { at } z \rightarrow \infty\end{array}\right\} \forall t>0$

(22)

\section{Method OF Solution}

By applying Galerkin finite element method for Eq. (19) over the element (e), $z_{j} \leq z \leq z_{k}$ is:

$\int_{z_{j}}^{z_{k}}\left\{N^{(e) T}\left[\begin{array}{l}\frac{\partial^{2} u^{(e)}}{\partial z^{2}}-\frac{\partial u^{(e)}}{\partial t}+\frac{\partial u^{(e)}}{\partial z} \\ -A u^{(e)}+P\end{array}\right]\right\} d z=0$

Where $\mathrm{A}=\frac{M}{1+m^{2}}, \mathrm{P}=A m v_{i}^{j}+\Omega v_{i}^{j}$;

Integrating the first term in Eq. (23) by parts one obtains

$$
\begin{aligned}
& N^{(e) T}\left\{\frac{\partial u^{(e)}}{\partial z}\right\}_{z_{j}}^{z_{k}} \\
& -\int_{z_{j}}^{z_{k}}\left\{\begin{array}{c}
\frac{\partial N^{(e) T}}{\partial z} \frac{\partial u^{(e)}}{\partial z}+ \\
\left.N^{(e) T}\left(\begin{array}{c}
\frac{\partial u^{(e)}}{\partial t}-\frac{\partial u^{(e)}}{\partial z} \\
+A u^{(e)}-P
\end{array}\right)\right\} d z=0
\end{array}\right.
\end{aligned}
$$

Neglecting the first term in Eq. (24), one gets:

$\int_{z_{j}}^{z_{k}}\left\{\begin{array}{l}\frac{\partial N^{(e) T}}{\partial z} \frac{\partial u^{(e)}}{\partial z}+ \\ N^{(e) T}\left(\frac{\partial u^{(e)}}{\partial t}-\frac{\partial u^{(e)}}{\partial z}+A u^{(e)}-P\right)\end{array}\right\} d z=0$

Let $u^{(e)}=N^{(e)} \varphi^{(e)}$ be the linear piecewise approximation solution over the element (e) 
where $\quad N^{(e)}=\left[\begin{array}{ll}N_{j} & N_{k}\end{array}\right], \varphi^{(e)}=\left[\begin{array}{ll}u_{j} & u_{k}\end{array}\right]^{T} \quad$ and $N_{j}=\frac{z_{k}-z}{z_{k}-z_{j}}, N_{k}=\frac{z-z_{j}}{z_{k}-z_{j}}$ are the basis functions. One obtains:

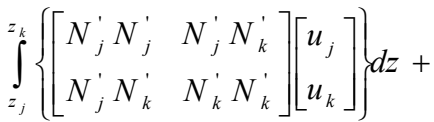

$$
\begin{aligned}
& \int_{z_{j}}^{z_{k}}\left\{\left[\begin{array}{ll}
N_{j} N_{j} & N_{j} N_{k} \\
N_{j} N_{k} & N_{k} N_{k}
\end{array}\right]\left[\begin{array}{c}
\cdot \\
\dot{u}_{j} \\
\dot{u}_{k}
\end{array}\right]\right\} d z \\
& -\int_{z_{j}}^{z_{k}}\left\{\left[\begin{array}{cc}
N_{j} N_{j}^{\prime} & N_{j} N_{k}^{\prime} \\
N_{j}^{\prime} N_{k} & N_{k}^{\prime} N_{k}
\end{array}\right]\left[\begin{array}{l}
u_{j} \\
u_{k}
\end{array}\right]\right\} d z+ \\
& A \int_{z_{j}}^{z_{k}}\left\{\left[\begin{array}{ll}
N_{j} N_{j} & N_{j} N_{k} \\
N_{j} N_{k} & N_{k} N_{k}
\end{array}\right]\left[\begin{array}{l}
u_{j} \\
u_{k}
\end{array}\right]\right\} d z \\
& =P \int_{z_{j}}^{z_{k}}\left[\begin{array}{c}
N_{j} \\
N_{k}
\end{array}\right] d z
\end{aligned}
$$

Simplifying we get

$$
\begin{aligned}
& \frac{1}{l^{(e)^{2}}}\left[\begin{array}{rr}
1 & -1 \\
-1 & 1
\end{array}\right]\left[\begin{array}{l}
u_{j} \\
u_{k}
\end{array}\right]+\frac{1}{6}\left[\begin{array}{ll}
2 & 1 \\
1 & 2
\end{array}\right]\left[\begin{array}{l}
\dot{u}_{j} \\
\dot{u}_{k}
\end{array}\right] \\
& -\frac{1}{2 l^{(e)}}\left[\begin{array}{rr}
-1 & 1 \\
-1 & 1
\end{array}\right]\left[\begin{array}{l}
u_{j} \\
u_{k}
\end{array}\right]+\frac{A}{6}\left[\begin{array}{ll}
2 & 1 \\
1 & 2
\end{array}\right]\left[\begin{array}{l}
u_{j} \\
u_{k}
\end{array}\right] \\
& =\frac{P}{2}\left[\begin{array}{l}
1 \\
1
\end{array}\right]
\end{aligned}
$$

where prime and dot denotes differentiation w.r.to ' $\mathrm{z}$ ' and time ' $t$ ' respectively. Assembling the element equations for two consecutive elements $z_{i-1} \leq z \leq z_{i}$ ] and $z_{i} \leq z \leq z_{i+1}$ following is obtained:

$$
\begin{aligned}
& \frac{1}{l^{(e)^{2}}}\left[\begin{array}{rrr}
1 & -1 & 0 \\
-1 & 2 & -1 \\
0 & -1 & 1
\end{array}\right]\left[\begin{array}{l}
u_{i-1} \\
u_{i} \\
u_{i+1}
\end{array}\right]+\frac{1}{6}\left[\begin{array}{lll}
2 & 1 & 0 \\
1 & 4 & 1 \\
0 & 1 & 2
\end{array}\right]\left[\begin{array}{l}
\dot{u}_{i-1} \\
\dot{u}_{i} \\
\dot{u}_{i+1}
\end{array}\right] \\
& -\frac{1}{2 l^{(e)}}\left[\begin{array}{rrr}
-1 & 1 & 0 \\
-1 & 0 & 1 \\
0 & -1 & 1
\end{array}\right]\left[\begin{array}{l}
u_{i-1} \\
u_{i} \\
u_{i+1}
\end{array}\right] \\
& +\frac{A}{6}\left[\begin{array}{rrr}
2 & 1 & 0 \\
1 & 4 & 1 \\
0 & 1 & 2
\end{array}\right]\left[\begin{array}{l}
u_{i-1} \\
u_{i} \\
u_{i+1}
\end{array}\right]=\frac{P}{2}\left[\begin{array}{l}
1 \\
2 \\
1
\end{array}\right]
\end{aligned}
$$

Now put row corresponding to the node 'i' to zero, from Eq. (25) the difference schemes with $l^{(e)}=h$ is:

$$
\begin{aligned}
& \frac{1}{h^{2}}\left[-u_{i-1}+2 u_{i}-u_{i+1}\right]+\frac{1}{6}\left[\dot{u}_{i-1}+4 \dot{u}_{i}+\dot{u}_{i+1}\right] \\
& -\frac{1}{2 h}\left[-u_{i-1}+u_{i+1}\right] \\
& +\frac{A}{6}\left[u_{i-1}+4 u_{i}+u_{i+1}\right]=P
\end{aligned}
$$

Applying the trapezoidal rule, following system of equations in Crank-Nicholson method are obtained:

$$
\begin{aligned}
& A_{1} u_{i-1}^{n+1}+A_{2} u_{i}^{n+1}+A_{3} u_{i+1}^{n+1}= \\
& A_{4} u_{i-1}^{n}+A_{5} u_{i}^{n}+A_{6} u_{i+1}^{n}+P^{*}
\end{aligned}
$$

Applying the same procedure to the Eq. (20) then the following equation is obtained:

$$
\begin{aligned}
& B_{1} v_{i-1}^{n+1}+B_{2} v_{i}^{n+1}+B_{3} v_{i+1}^{n+1}={ }^{\prime} \\
& B_{4} v_{i-1}^{n}+B_{5} v_{i}^{n}+B_{6} v_{i+1}^{n}+Q^{*}
\end{aligned}
$$

where $A_{1}=2+A k+3 r h-6 r$;

$$
\begin{aligned}
& \mathrm{A}_{2}=4 \mathrm{Ak}+12 \mathrm{r}+8 ; \\
& \mathrm{A}_{3}=2+\mathrm{Ak}-3 \mathrm{rh}-6 \mathrm{r} ; \\
& \mathrm{A}_{4}=2-\mathrm{Ak}-3 \mathrm{rh}+6 \mathrm{r} ; \\
& \mathrm{A}_{5}=8-4 \mathrm{Ak}-12 \mathrm{r} ; \\
& \mathrm{A}_{6}=2-\mathrm{Ak}+3 \mathrm{rh}+6 \mathrm{r} ; \\
& \mathrm{B}_{1}=2-\mathrm{Ak}+3 \mathrm{rh}-6 \mathrm{r} ; \\
& \mathrm{B}_{2}=8+12 \mathrm{r}-4 \mathrm{Ak} ; \\
& \mathrm{B}_{3}=2-\mathrm{Ah}-3 \mathrm{rh}-6 \mathrm{r} ; \\
& \mathrm{B}_{4}=2+\mathrm{Ak}-3 \mathrm{rh}+6 \mathrm{r} ; \\
& \mathrm{B}_{5}=8+4 \mathrm{Ak}-12 \mathrm{r} ; \\
& \mathrm{B}_{6}=2+\mathrm{Ak}+3 \mathrm{rh}+6 \mathrm{r} ; \\
& P^{*}=12 k A m v_{i}^{j}+12 k \Omega v_{i}^{j} ; \\
& Q^{*}=12 k A m u_{i}^{j}-12 k \Omega u_{i}^{j} ;
\end{aligned}
$$

Here $\mathrm{r}=\frac{k}{h^{2}}$ and $\mathrm{h}, \mathrm{k}$ are mesh sizes along $\mathrm{y}$-direction and time-direction respectively. Index ' $i$ ' refers to space and ' $\mathrm{j}$ ' refers to the time. In the Eqs. (27) and (28) taking $\mathrm{i}=1(1) \mathrm{n}$ and using boundary conditions (21) and (22), then the following system of equations are obtained:

$$
A_{i} X_{i}=B_{i} \quad i=1(1) 2
$$

where $A_{i}^{\prime} \mathrm{s}$ are matrices of order $\mathrm{n}$ and $X_{i}, B_{i}^{\prime} \mathrm{s}$ are column matrices having n-components. The solutions of above system of equations are obtained by using Thomas algorithm for primary velocity and secondary velocity. Also, numerical solutions for these equations are obtained by $\mathrm{C}$ - programme. In order to prove the convergence and stability of Galerkin finite element method, the same $\mathrm{C}$ - programme was run with smaller values of $\mathrm{h}$ and $\mathrm{k}$ and no significant change was observed in the values of $u$ and $v$. Hence the Galerkin finite element method is stable and convergent.

\section{SHEAR STRESS}

The skin friction at the plate in the direction of the primary velocity is given by

$\tau_{x}=-\left[\frac{\partial u}{\partial z}\right]_{z=0}$ 
The skin friction at the plate in the direction of the secondary velocity is given by

$$
\tau_{y}=-\left[\frac{\partial v}{\partial z}\right]_{z=0}
$$

\section{RESUlts AND Discussions}

In order to study the effect of magnetic field for flow configuration shown in Fig. 1, Hall current and rotation of the fluid, we have carried out numerical calculations for the dimensionless primary velocity $\mathrm{u}$, secondary velocity $\mathrm{v}$ and skin frictions $\tau_{x}$ and $\tau_{y}$ at the plate due to the primary and secondary velocity fields respectively for different values of the rotation parameter $\Omega$, Hartmann number $\mathrm{M}$ and Hall parameter $\mathrm{m}$ keeping the value of time $\mathrm{t}$ fixed at $\mathrm{t}=1$.

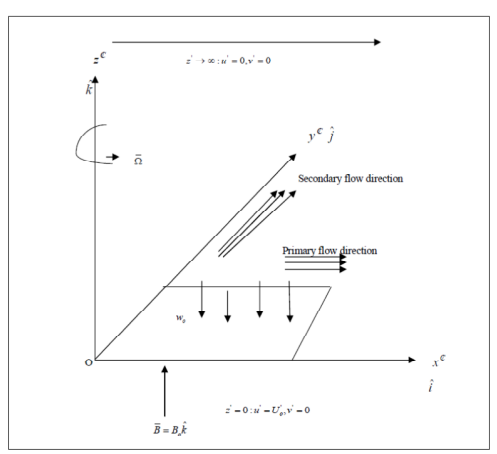

Fig. 1. Flow configuration

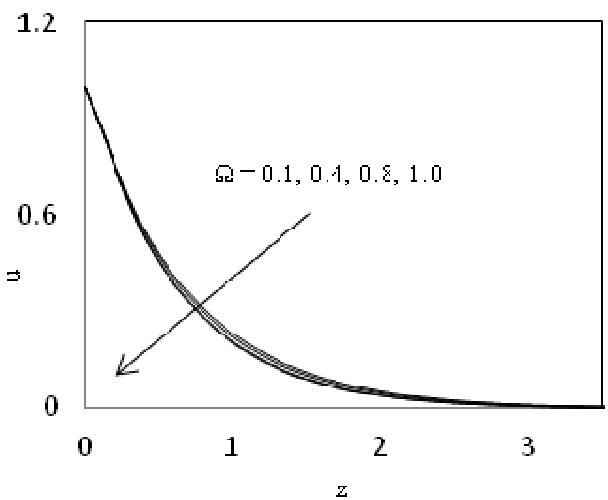

Fig. 2. The primary velocity ' $u$ ' versus ' $z$ ' for $M=1.0$, $\mathrm{m}=0.5, \mathrm{t}=1$

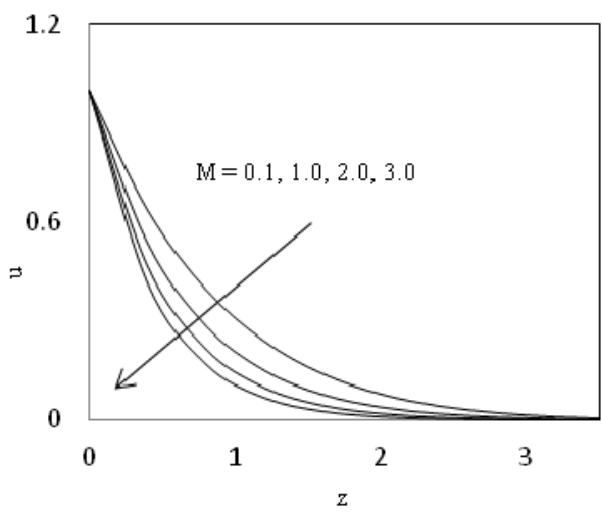

Fig. 3. The primary velocity ' $u$ ' versus ' $z$ ' for $\Omega=0.4$, $\mathrm{m}=0.5, \mathrm{t}=1$
Figures 2, 3 and 4 exhibit the variation of the primary velocity $\mathrm{u}$ versus $\mathrm{z}$ under the influence of the rotation parameter $\Omega$, Hartmann number $\mathrm{M}$ and the Hall parameter $\mathrm{m}$. These three figures show that the primary velocity $\mathrm{u}$ falls when $\Omega$ and $\mathrm{M}$ are increased, it rises due to increasing value of the Hall parameter $\mathrm{m}$. That is the primary motion is retarded under the effects of the transverse magnetic field and the rotation of the fluid where as this motion is accelerated under the Hall Effect. This phenomenon is clearly supported by the physical reality. The same figures further establish the fact that the primary velocity asymptotically decreases from maximum value $u=1$ to its minimum value $u=0$ as $\mathrm{z}$ increases.

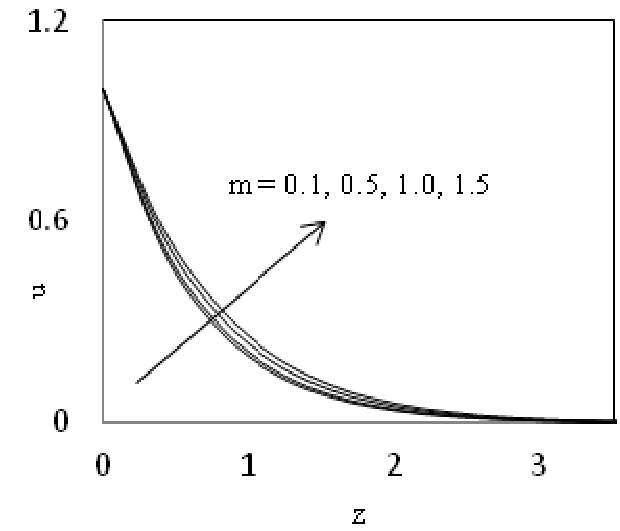

Fig. 4. The primary velocity ' $u$ ' versus ' $z$ ' for $M=1.0$, $\Omega=0.4, \mathrm{t}=1$

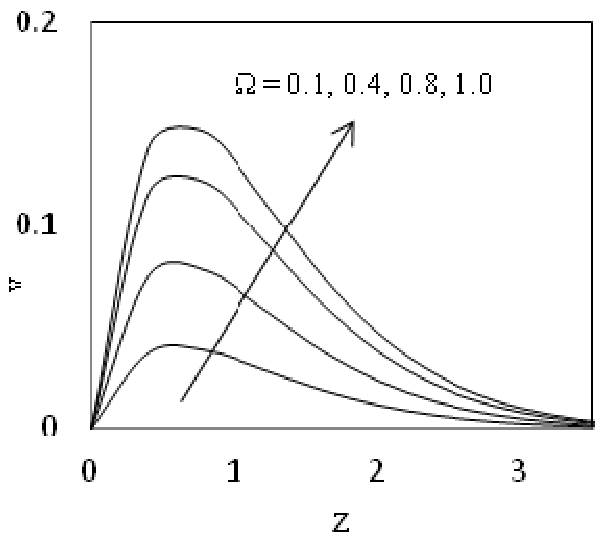

Fig. 5. The secondary velocity ' $v$ ' versus ' $z$ ' for $\mathrm{M}=1.0, \mathrm{~m}=0.5, \mathrm{t}=1$

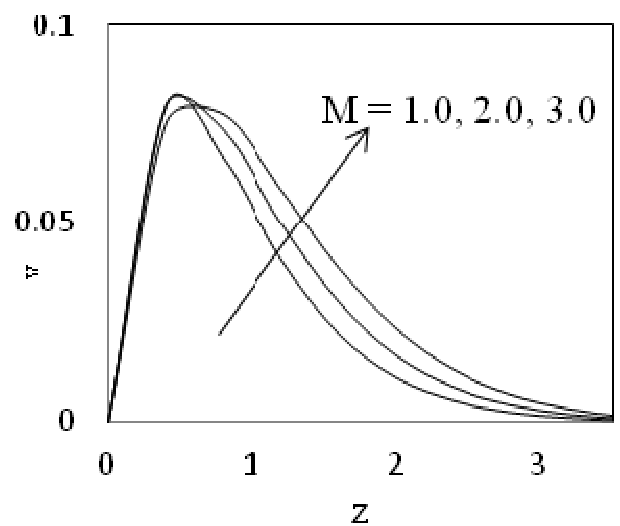

Fig. 6. The secondary velocity ' $v$ ' versus ' $z$ ' for $\Omega=0.4, \mathrm{~m}=0.5, \mathrm{t}=1$ 
The change of behaviour of the secondary velocity $\mathrm{V}$ against $\mathrm{z}$ due to variations of $\Omega, \mathrm{M}$ and $\mathrm{m}$ is displayed in Figs. 5, 6 and 7. It is inferred from these figures that are velocity field first increases in a very thin layer adjacent to the plate and after this layer it asymptotically decreases to its zero value as $\mathrm{z}$ increases. It is also marked from these figures that an increase in the value of the parameters $\Omega, \mathrm{M}$ and $\mathrm{m}$ results in a steady growth in $\mathrm{v}$. in other words it may be stated that the secondary motion is accelerated under the effects of Hall current and rotation and due to the application of the transverse magnetic field.

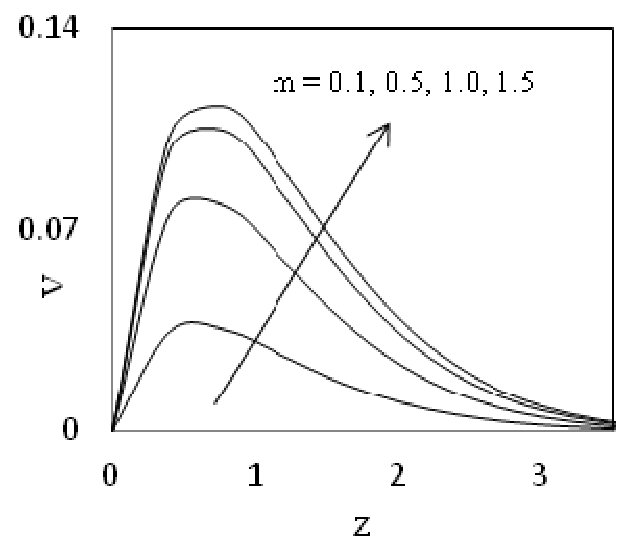

Fig. 7. The secondary velocity ' $v$ ' versus ' $z$ ' for $\mathrm{M}=1.0, \Omega=0.4, \mathrm{t}=1$

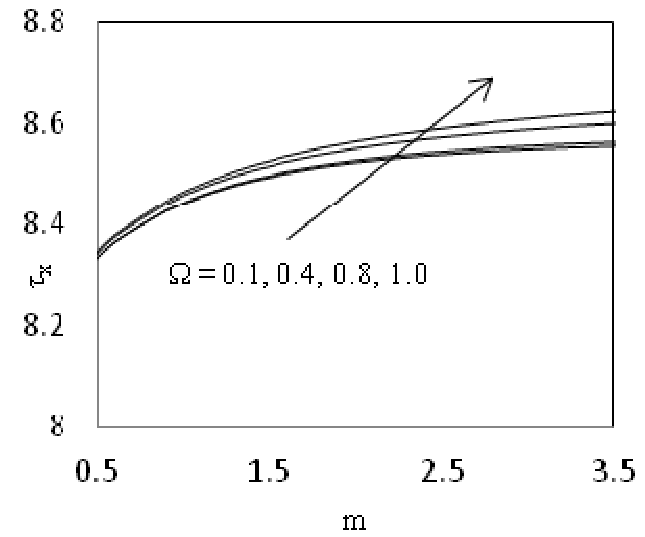

Fig. 8. The skin friction ' $\tau_{\mathrm{x}}$ ' versus ' $\mathrm{m}$ ' for $\mathrm{M}=1.0$, $\mathrm{t}=1.0$

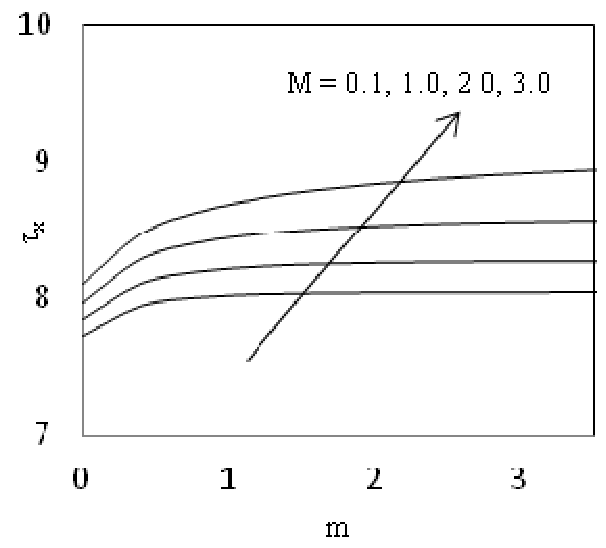

Fig. 9. The skin friction ' $\tau_{\mathrm{x}}$ ' versus ' $\mathrm{m}$ ' for $\Omega=0.4$, $\mathrm{t}=1.0$
The profiles for skin-friction $\tau_{x}$ due to primary velocity under the effects of $\Omega, \mathrm{M}$ and $\mathrm{m}$ are presented in the Figs. 8 and Fig. 9. We see from these figures that when the strength of the applied magnetic field and the angular velocity of rotation of the fluid are increased the skin-friction $\tau_{x}$ increases and $\tau_{x}$ falls due to Hall effect. From this observation we may interpret that the viscous drag on the plate due to primary motion is reduced under Hall Effect, but this frictional force increases under the effects of the magnetic field and rotation.

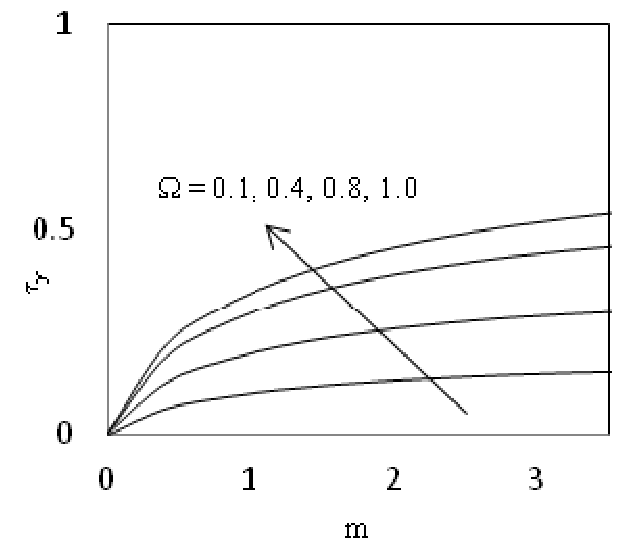

Fig. 10. The skin friction ' $\tau$ ' versus ' $m$ ' for $\mathrm{M}=1.0, \mathrm{t}=1.0$.

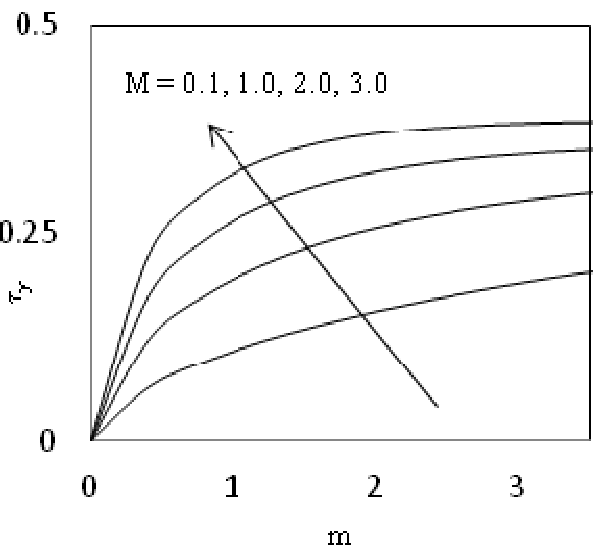

Fig. 11. The skin friction ' $\tau_{\mathrm{y}}$ ' versus ' $\mathrm{m}$ ' for $\Omega=0.4, \mathrm{M}=1.0, \mathrm{t}=1.0$

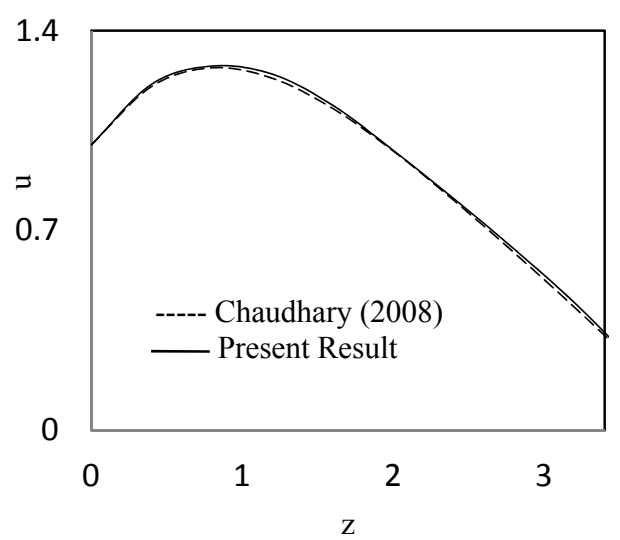

Fig. 12. Comparison of primary velocity ' $u$ ' versus ' $z$ ' for $\mathrm{m}=0.5, \mathrm{M}=1.0, \Omega=0.4$ and $\mathrm{t}=1.0$. 
Figures 10 and 11 demonstrate the variation of skinfriction $\tau_{y}$ due to the secondary velocity under the effects of $\Omega, M$ and $\mathrm{m}$. It is seen that $\tau_{y}$ rises under the effects of $M$ and $\Omega$. These figures further predict that for small and moderate values of $\mathrm{m}, \tau_{y}$ rises as $\mathrm{m}$ increases but for large values of $\mathrm{m}$ this behaviour takes reverse trend.

In order to ascertain the accuracy of the Galerkin finite element method, the present results are compared with the previous results of Chaudhary (2008) for $\mathrm{M}=1.0$, $\Omega=0.4, \mathrm{t}=1$ in Fig. 12. They are found to be in an excellent agreement.

\section{Conclusion}

Our results of investigation may be summarized to the following important conclusions.

1. The primary motion is retarded under the effects of transverse magnetic field and the rotation of the fluid where as this motion is accelerated under the Hall Effect.

2. The secondary motion is accelerated under the effects of the Hall current and rotation and due to the application of the transverse magnetic field.

3. The viscous drag due to primary motion is reduced under Hall Effect, but this frictional force increases under the effects of the magnetic field and rotation.

4. The skin-friction $\tau_{y}$ due to secondary velocity rises under the effects of the Hartmann number $\mathrm{M}$ and the angular velocity of rotation $\Omega$.

\section{REFERENCES}

Abdul Maleque, Kh. and Md. Abdur Sattar (2005). The Effects of Variable properties and Hall current on steady MHD laminar convective fluid flow due to a porous rotating disk. Int. Journal of Heat and Mass Transfer 48, 460 - 4466.

Aboeldahab, E.M. and E.M.E. Elbarbary (2001). Hall current effect magneto hydrodynamics free convection flow past a semi infinite vertical plate with mass transfer, Int. J. Engg. Sci. 39, $1641-1652$.

Acharya, M., G.C. Dash and L.P Singh (2001). Hall effect with simultaneous thermal and mass diffusion on unsteady hydromagnetic flow near an accelerated vertical plate. Ind. J. Physics. B. $75 \mathrm{~B}, 68-70$

Chaudhary R. C. and A. Kumar Jha (2008). Heat and mass transfer in elastico -viscous fluid past an impulsively started infinite vertical plate with Hall Effect. Latin American Applied Research 38, 17 26.

Cowling, T.G. (1957). Magneto Hydrodynamics. Wiley Inter Science, New York.
Crammer, K. P. and S.L. Pai (1978). Magneto-fluid Dynamics for Engineers and Applied Physics. McGraw Hill book Co New York.

Das, U.N, R. Deka and V.M. Soundalgekar (1996). Radiation effects on flow past an impulsively started vertical plate-an exact solutions. J. Theo. Appl. Fluid Mech. 1(2), $111-115$.

Datta, N. and R.N. Jana (1976). Oscillatory magnetohydrodynamic flow past a flat plate wilth hall effects. J. Phys. Soc. Japan 40, 1469.

Ferraro, V.C.A. and C. Plumpton (1966). An Introduction to Magneto Fluid Mechanics. Clarandon Press, Oxford.

Ganesan, P. and G. Palani (2002). The effects of mass transfer on the MHD flow past an impulsively started isothermal inclined plate. Journal of Energy, Heat and Mass Transfer 24, 1 - 12.

Kinyanjui, M., J.K. Kwanza and S.M. Uppal (2001). Magnetohydrodynamic free convection heat and mass transfer of a heat generating fluid past an impulsively started infinite vertical porous plate with Hall current and radiation absorption. Energy Conservation and Management. 42, 917 931.

Muthucumaraswamy, R., and P. Ganesan (1998). Unsteady flow past an impulsively started vertical plate with heat and mass transfer. Journal of Energy, Heat and Mass Transfer 34, 187-193.

Palani, G. and I.A. Abbas (2009). Free convection MHD flow with thermal radiation from an impulsively started vertical plate. Nonlinear Analysis: Modelling and Control 14(1), 73 - 84.

Prasad, V.R., N. Bhaskar Reddy and R. Muthucumaraswamy (2011). Finite Difference analysis of radiative free convection flow past an impulsively started vertical plate with variable heat and mass flux. Journal of Applied Fluid Mechanics 4(1), 59 - 68 .

Prasad, V.R., N. Bhaskar Reddy and R. Muthucumaraswamy (2007). Radiation and mass transfer effects on two- dimensional flow past an impulsively started infinite vertical plate. Int. J. Thermal Sciences 46(12), 1251 - 1258.

Prasad, V.R., N. Bhaskar Reddy and R. Muthucumaraswamy (2006). Transient radiative hydromagnetic free convection flow past an impulsively started vertical plate with uniform heat and mass flux, Theoretical Applied Mechanics $33(1), 1-63$.

Sharma, B.K., A.K. Jha and R.C. Chaudhary (2007). Hall Effect on MHD Mixed Convective Flow of a Viscous Incompressible Fluid Past a Vertical Porous Plate Immersed in Porous Medium with Heat Source/Sink. Rom. Journal Phys 52(5), 487 503. 
Shercliff, J.A. (1965). A Text Book of Magneto Hydrodynamics. Pergamon Press, London.

Singh, K.D. (2000). An oscillatory hydromagnetic Couette flow in a rotating system. ZAMM 80, 429 $-432$

Suneetha, S., N. Bhaskar Reddy and V. Ramachandra Prasad (2011). Radiation and Mass transfer effects on MHD free convective Dissipative fluid in the presence of heat source/sink. Journal of Applied Fluid Mechanics 4(1), 107 - 113.

Takhar, H.S., A. J. Chamkha and G. Nath (2002). MHD flow over a moving plate in a rotating fluid with magnetic field, Hall currents and free stream velocity. Int. J. Engng Sci. 40(13), 1511 - 1527.

Vasu B, V. Ramachandra Prasad and N. Bhaskar Reddy (2011). Radiation and mass transfer effects on transient free convection flow of a dissipative fluid past semi-infinite vertical plate with uniform heat and mass flux. Journal of Applied Fluid Mechanics 4(1), 15 - 26. 